\title{
Climate Smart Food Supply Chains in Developing Countries in an Era of Rapid Dual Change in Agrifood Systems and the Climate
}

\author{
Thomas Reardon and David Zilberman
}

\begin{abstract}
Food supply chains are essential to food security in developing regions where today the great majority of food consumed is purchased from rural-urban, rural-rural, and urban-rural supply chains. Disrupting those supply chains means disrupting food security. Yet short-term climate shocks and long-term climate change threaten to cause that disruption. This chapter does four things: (1) analyzes the types and determinants of vulnerabilities of food supply chains to climate shocks and change; (2) considers how those vulnerabilities are conditioned by urbanization, diet change, and rapid transformation of food systems; (3) discusses how supply chain actors, from farmers to processors and distributors and input suppliers, invest in mitigation of the risks of these shocks and reduction of their vulnerabilities; (4) discusses policy implications and lays out an agenda for research for climate smart food supply chains in developing regions.
\end{abstract}

\section{Introduction}

The literature on Climate Smart Agriculture (CSA) has mostly ignored that farming of a given product, like fish, fruit or milk, occurs within a complex supply chain. Even CSA literature on "food systems" (such as FAO's book on this theme, Elbehri (ed.) Elbehri 2015) tends to focus on biophysical dimensions of climate change in farm areas, not all the way along supply chains. This chapter aims at that gap.

The supply chain has a complex dendritic cluster structure composed of three dimensions:

\footnotetext{
T. Reardon $(\bowtie)$

Department of Agricultural, Food and Resource Economics, Michigan State University,

East Lansing, MI, USA

e-mail: reardon@msu.edu

D. Zilberman

Department of Agriculture and Resource Economics, University of California Berkeley,

Berkeley, CA, USA
} 
(a) Four main segments of the product's supply chain, with flow from upstream to downstream: (1) farm input supply chains, which are "upstream" of farms; (2) the farm segment, which forms approximately half of the full costs and value added of food supply chains in developing countries (Reardon 2015); (3) the "midstream" segment consisting of processing, wholesale, and transport; and (4) the "downstream" segment consisting of retailing (stores and restaurants).

(b) Supply chains of innovation (R\&D) supply innovations for the technologies, institutions, and organizations of each segment.

(c) Input supply chains upstream of each segment provide inputs to it such as equipment to fertilizer manufacturers and fuel to transporters.

This three-dimensional cluster is important to food security and livelihoods as well as vulnerable to climate shocks. These complex supply chains are important for food security because they provide $90 \%$ of urban consumers' food in Africa and Asia (the other 10\% from imports) (Reardon 2016). Further, our research shows that $50-80 \%$ of rural diets (in value terms) in Africa and Asia come from purchased food. We also found that nearly $100 \%$ of rural households in Asia, and $98 \%$ in Africa, buy food and thus depend on the supply chain for food security. With respect to rural livelihoods, supply chains provide supply inputs to farmers and households depend on them as sales conduit to urban areas, the main markets in developing countries. Moreover, the off-farm components of the supply chains, such as transport, commerce and processing and handling, are key sources of employment in rural areas for a majority of rural households, and of cash for farm investments.

Finally, while conventional wisdom tends to see domestic food supply chains in developing regions as traditional and stagnant, in fact they have transformed greatly. The transformation has involved moving from traditional short fragmented chains to transitional and modern forms in developing regions. This is discussed in more detail in Sect. 2. Supply chains have grown massively in volume and length as the urban areas served rapidly expand and reach out into rural areas. Supply chains have transformed rapidly in structure - such as the rise of supermarkets and large processors, and in product composition - with a concurrent shift in diets toward processed foods, and non-grain products such as milk, meat, fish, fruits, and vegetables (Tschirley et al. 2015). They have also transformed rapidly in conduct - with basic changes in food processing and transport technology, and with the rise of standards and contracts (Swinnen 2007).

A crucial point is that short-term climate shocks and long-term change can heavily affect not just the farm segment of the above complex supply chains, but also the segments upstream and downstream from the supply chain's "four legged chair", as well as the input supply chains to all those segments. These shocks and changes can be challenging - even fundamentally disruptive - to these complex chains, endangering food security and livelihoods for both rural and urban households. For these reasons, to develop CSA systems we need to understand all three dimensions of food supply chains, how the three off-farm segments respond to climate change and shocks, how farmers do and should react to these responses, and then what type of policies are needed to take into account the complete supply chain. 
Moreover, climate smart supply chains must consider that the short run and long run impacts of climate change are different, and thus so are short-term and longterm impact of and response to climate change. In the shorter run, we may observe increased probabilities of extreme climatic events such as typhoons and droughts, which shock agriculture and disrupt supply chains (Kleindorfer and Saad 2005). These require risk management and climate shock coping innovations in supply chains. For most agrifood companies, the short-term climate shocks dominate their climate-related concerns as they are issues of immediate business survival; all but the largest companies are forced to have short-run planning horizons.

In the longer run, climate change may affect the configuration of agricultural supply chains. The changes include migration of weather patterns from the equator towards the poles, melting snow and ice, and rising sea levels (Nicholls and Cazenave 2010). This may require that supply chains adapt by shifting supply zones and innovating structurally to new configurations. These will appear as short-term shock adaptations over time; but they will also appear as long-term planning issues for the largest companies and governments. Adaptation may appear in the form of introduction and adoption of new innovations, changes in land use and trade patterns, migration, increased reliance on insurance, and increased investment to enhance resilience of farming operations as well as distribution and processing (Zilberman et al. 2012). Each of these activities has significant impacts on the organization of agriculture and agricultural supply chains over time.

A research agenda on the impact of climate change on simple and complex agricultural supply chains is essential to comprehend its impacts and in developing policies and mechanisms to address them. A literature has emerged on managing risks of disruption in nonfood manufactures supply chains (e.g., Oke and Gopalakrishnan 2009), but there has been little on this topic for food supply chains, let alone with climate crises and change as the cause of the disruption.

Moreover, climate changes manifested in both short-term crises and long-term changes represent a new and complex set of shocks that call on researchers to alter the way supply chains are studied; that is, to date, supply chain contexts have been taken to be either static or only slowly changing, and hanging along one or other particular dimension, such as urbanization or market liberalization. By contrast, climate change represents fundamental increases in unanticipated risk as well as basic changes in the agroecological contexts of the supply chain. In addition, climate change will result in new innovations that are likely to lead to modifications and changes in supply chains (Du et al. 2016). These will require an agenda of research on new methods and models of understanding these changes.

The next section presents the main patterns of transformation of supply chains. It will be followed by two sections discussing the short and long-term climate changes, their impacts on supply chains, and the measures post-harvest actors take to mitigate these impacts. In the conclusion we offer initial implications of these changes for the climate change debate and propose policy implications and a research agenda. 


\section{Background: Up-to-Date Vision of Transforming Supply Chains in Africa and Asia as Basis for Assessment of Climate Impacts}

To assess the challenges of climate change and shocks on food supply chains, it is crucial to have a realistic and up-to-date vision of what food supply chains have become in Africa and Asia. The transformation of complex supply chains has taken place at somewhat different speeds and extent over products and zones as well as countries and regions. Farmers relying on traditional supply chains (short, fragmented, and with low dependency on infrastructure and equipment) are paradoxically exposed to more income risk from local climate shocks as their overall livelihood is less commercialized and more dependent on the vicissitudes and low purchasing power of the local economy. At the same time, traditional supply chains are less exposed to climate shocks that can occur along geographically longer and more complex supply chains.

Moreover, while modern supply chains have more sources of vulnerability than traditional chains, the modern chains also have potentially more means to escape from and mitigate climate vulnerability. For example, longer chains afford much greater chances to increase overall income and manage risk through market engagement. Altogether, whether the farmer who depends on traditional or modern supply chains is exposed to lower overall risk is an empirical question that will vary by place and crop. It can be addressed with respect both to the degree of transformation (modernization) of the supply chains and the degree to which post-harvest actors in the supply chain invest in climate-mitigating technologies and institutions.

At the essence of transformation is a system that is local, grain focused, small scale, spot market, and labor or land intensive to a system with geographically long supply chains, a diversified product portfolio, coordination institutions such as standards and contracts, varying degrees of disintermediation and consolidation, and increasingly capital-intensive technology used in each of the segments. In general the transformation has developed around two broad axes. The first is structural, including change in the number of segments and sub-segments of agrifood value chains (VCs), and the degree of concentration and ownership of capital (public versus private, domestic versus foreign) per segment. The second is behavioral, including how actors per segment buy, make, and sell, and the choices made of technology, institutions (like standards and contracts) and organizations (like vertical and horizontal integration and coordination). This transformation is led by a rapidly urbanizing population, domestically sourced food in Africa and Asia and increasing food purchases by rural populations.

First, urbanization has been very rapid, and the urban share in national food markets is now dominant, or nearly so. In (developing) Eastern and Southern Africa (ESA), 30\% of the population is urban but represents $40 \%$ of national food consumption, and roughly $50 \%$ of food market purchases. In West Africa, those shares are roughly $40 \%, 50 \%$, and $60 \%$, and in China and Southeast Asia, roughly $45 \%$, $55 \%$, and $65 \%$, respectively. These numbers are surprising in national debates in 
Africa and Asia partly because, as we perceive it, the extent and importance of urbanization has not yet entered national food security debates, and because the image of large rural populations dominating food needs is a persistent vestige of the situation only a decade or two ago when the urban market was a small niche market. Further, urban consumption volumes have become massively larger. Rural-urban food supply chains have expanded 800\% in Africa, 300\% in South Asia, 1000\% in Southeast Asia over the past three decades. The key implication of this for climate shock vulnerability is that the length of supply chains is growing as urban areas source further afield.

Second, the great majority of food supply in Africa and Asia is from domestic sources; food imports are only about $10 \%$ of total food consumption in Africa and Asia. Driven by food security issues, we focus mainly on domestic supply chains. The implication for the climate change debate is that the great majority of food supply is vulnerable to climate shocks internal to particular developing countries. Still, international supply chains that provide the small share $(10 \%)$ of the domestic food supply from imports, or convey the 5-10\% of farm incomes that come from exports, are vulnerable to climate shocks on long maritime passages as well as to policy shocks such as export bans.

Third, rural households have shifted from subsistence farming to depending more on food purchases. In ESA, the share represents $45 \%$ of total rural food expenditures (meaning $45 \%$ of their food consumption comes from purchases and 55\% from own-farm production) and in Asia 60-70\% of total rural food expenditures.

These first three points imply that climate vulnerability issues along a supply chain can be divided directionally, namely: (1) rural to urban ("rural-urban") supply chains; (2) rural to rural ("rural-rural"); (3) urban to rural ("urban-rural"). To date the vast majority of research on supply chains has been international or rural-urban. We focus here on domestic rural-urban supply chains and leave to future analysis (based on field research currently being conducted in Africa) to elucidate the transformations of the other two types of supply chains and explore to what extent they have climate vulnerabilities and strategies that differ from rural to urban chains.

Rural-urban food supply chains are transforming rapidly, consolidating, and undergoing technological change. Transformation is occurring in terms of growth in supply chain volume, rapid diversification beyond grains, and increasing delivery of processed foods. For example, in ESA non-grains in urban household total food expenditure (TFE) is $66 \%$, while rural is $61 \%$. This implies more perishable goods and thus increased vulnerability to transport and storage conditions, which affect food safety and food loss. Processed foods in Asia constitute 73\% of TFE in urban, and 60\% in rural TFE; in ESA 56\% of urban TFE and 29\% of rural TFE. Processing is vulnerable to energy and climate shocks in two primary ways. First is availability of energy supply due to cost, reliability of the grid, and transportation routes. Second is delays in transportation that result in spoilage. In the past, drying, salting, and pickling reduced vulnerability to delays, but the shares of these technologies are declining, even in developing countries, as fast transport chains and cold storage, which are more vulnerable, take over. 
Post-harvest consolidation is occurring in two ways. Supply chains are becoming "intermediationally shorter", which implies consolidation over actors transporting food. This is increasing the scale of transport vehicles and wholesale/logistics and further concentrating transport. In retail, consolidation is occurring with the rapid rise of supermarkets, processing, wholesale/logistics, and agricultural input sectors. These changes are driven, in part, by a rise in the share of foreign direct investment (FDI), or "multinationalization". Both changes imply a concentration of the effects of climate change over fewer actors. Finally, technological change is resulting in a greater reliance on energy production with more dependence on equipment, as shown through an increase in the capital-labor ratio.

\section{Short-Term Climate Change Impacts on Transforming Food Supply Chains}

\subsection{Impacts on Food Supply Chains from Short-Term Climate Change}

Short-term climate shocks increase climate vulnerability and can be measured at various points along the supply chain. Climate-shock vulnerability points are called "hotspots" in the energy or food safety or phytosanitary literature (Giorgi 2006). Hotspots occur both in segments themselves (such as cold storage points, dry storage points, processing points, farming points, and input delivery paths to farms) as well as in sub-segments or individual operation points (such as mountain feeder roads to main highways) and input ingress points (such as water canals for farms or fuel, or electricity delivery interfaces). Vulnerability at each hotspot is dependent on the type of shock and attributes of a given segment. Further, the points need not be directly in the supply chain, but rather in secondary supply chains that feed into the product supply chain.

Examples of short-term climate shocks are floods or hillside rock avalanches on highways, tidal wave or typhoon destruction of sea or river ports or disruption of energy or fuel sources. These changes can disrupt or stop the product or input flow, especially along longer supply chains. For example, large poultry production and processing in Thailand by CP Foods relies on grain imports from the United States and imports chicken parts to China and Russia. A stoppage of operation in one of the facilities may disrupt production throughout the system, and may be very costly. Along a domestic supply chain, poultry production for urban consumption in Bangladesh or Nigeria relies on feed ingredient shipments from grain and cassava zones to peri-urban feed and poultry production facilities, which are vulnerable to road flood-outs and political strife (Liverpool-Tasie et al. 2016 for Nigeria).

A key point is that vulnerability of a supply chain often increases with the number and nature of hotspots. Further, the number and nature of the hotspots are in turn functions of the structure, conduct, and performance of the supply chain. We can 
categorize these conditioning factors, which are elements of the transformation of the supply chain, as follows.

The first determinant of a hotspot in the supply chain is the physical infrastructure affecting production risk in the supply area. The irrigation and drainage and flood control infrastructure upstream in the farming area is a crucial conditioner of the impact of drought and flooding shocks. This kind of private and public infrastructure is present far more in Asia, particularly East and Southeast Asia and in some zones of South Asia, and far less in Africa (Rosegrant et al. 2009). This discrepancy highlights the relative vulnerabilities by geography.

The second factor is the geographic distance along the supply chain. Longer geographic distance to the farm zone, and/or longer "lead time" from the assemblage and first stage processing and the final processing and demand points, increase vulnerability to climate shocks. There is however a trade-off between the vulnerability this implies and the diversification of urban food supply sources that long supply chains afford, which could reduce vulnerability to some degree. Even so, the rapid urbanization in both Africa and Asia is resulting in longer supply chains with increased climate vulnerability.

The third factor is the degree of product perishability. The greater the perishability of the product, and thus the need for fast delivery and/or cold storage, the greater the vulnerability to climate shock. This factor again increases climate vulnerability in Africa and Asia as the diet transformation has brought a huge surge in the demand for perishables.

A fourth factor is physical intensity in a given segment (e.g. irrigation, farm equipment, cold storage, delivery trucks). The robustness of physical capital is a key element in the vulnerability of supply chains to climate shocks. An example is the widespread damage to flimsy bamboo greenhouses on Java during unexpectedly virulent storms in the past few years. There is a general tendency for the capital/ labor ratio to rise in food supply chains as one moves from traditional to transitional to modern chains, which increases vulnerability. That tendency is for three reasons: (1) the labor market tends to tighten with urbanization and physical capital substitutes for labor; (2) physical capital enables supply chain managers to reduce vulnerability by off-setting climate-imposed costs with economies of scale, and reducing transport times with larger vehicles and inter-modal facilities, and increased cost competition in commoditizing supply chains further drives this investment; and (3) increased quality competition in modernizing supply chains increases equipment needs to achieve quality and safety attributes from suppliers to meet buyer requirements and standards. Growing dependence of suppliers and buyers on "assetspecific investments" may increase incentives to protect these assets from climate shocks (such as by investments in flood control).

A fifth factor is the location specificity of production or intermediation. Vulnerability to climate change decreases with more interchangeable places to produce a crop or handle it logistically. Location specificity, as a special case, can be linked to asset-specificity in that buyers depend on, are perhaps "locked into," sourcing from a farm zone or intermediation point due to specialized resources, firms or farms. This in a sense "holds hostage" the supply chain to these locations 
and thus to climate shocks they undergo. The "lock in" may run both ways - suppliers may be dependent on specific buyers in order to make profitable the specific investments they have made for that relationship. Moreover, asset specificity tends to be correlated with the product being a "differentiated product" instead of a commodity competing only on cost.

In a situation where there is a confluence of location and asset specificity and product differentiation, suppliers and buyers may have a strong incentive to invest in climate shock mitigation to protect the mutually profitable linkage. However, climate shocks may reach a level that requires too high an investment in mitigation for the linkage to be profitable, at which point the buyer or supplier would back away from this linkage. For example, a buyer who requires a high level of food safety (and thus low pesticide use), may break away from a given zone when climatic changes increase insect density to the point where more pesticide use is required to have acceptable fruit cosmetic quality, and thus make it uneconomic to rely on that zone.

Further, supply chain networks such as a supermarket chain source from several different zones (such as occurs in Mexico for tomatoes, see Reardon et al. 2007) over the year in order to smooth product supply inter-seasonally. While inter-season average vulnerability may remain low, periodic shocks due to climate or violence may increase dependence (such as in the North-South maize supply to feed mills for chicken and fish in Southern Nigeria; see Liverpool-Tasie et al. 2016). Sixth, more concentrated (as defined by industrial organizational terms) segments of the supply chain may either increase or decrease vulnerability to climate shocks. On the one hand, concentrating a process in a single large firm rather than in many small firms could make the process more risky (such as happened in the US in 1993 when the beef supply of the large chain Jack in the Box was tainted by E. coli from a single source and then infected the many points of supply). However, large companies have the means to make the "threshold investments" needed to mitigate or cope with a climate shock, as discussed in the next sub-section.

Finally, a seventh factor is variation over time in one location and over locations in the exposure to climate risk, controlling for the nature and occurrence of the hotspots per se. This acts as a magnifier and complement to the above six determinants of whether a point in the supply chain is a hotspot.

In sum, the determinants of hotspots described above, namely physical infrastructure to reduce production risk in supply zones, geographic length of the supply chain, perishability of the product, intensity and robustness of physical capital, asset specificity cum location specificity, concentration, and exposure to climate risk) generate a large number of "hotspots" in developing country food supply chains, before and after the farm gate. They also vary enormously over locations and products and the degree of transformation of supply chains. That implies that solutions to climate risk for supply chains will need to be highly differentiated and adapted to varying circumstances.

Moreover, these determinants are present in all directions of supply chains, including rural-urban chains, urban-rural, and rural-rural. While research on this is still in its infancy, we surmise that rural-urban and urban-rural supply chains, 
compared with rural-rural, will tend to have better infrastructure, be as long, involve more perishable products, and be more concentrated and asset-specific than ruralrural supply chains. This difference likely arises because rural-rural chains move more grains and tubers and shelf-stable vegetables like potatoes, while rural-urban and urban-rural, which include cities as origins or destinations, are more varied in product terms and more transformed in industrial organization terms.

\subsection{Impacts on Supply Chain Structure/Conduct/Performance of Short-Term Climate Shocks from Strategic Responses of Supply Chain Actors}

Enterprises in any segment of the supply chain, including input firms, farms, processors, and distributors, can be said to maximize utility under constraints. Utility derives from the level and stability of profits, which are a function of costs, product quality and safety (the latter two being in turn a function of requirements derived from the governance of the supply chain, such as the degree to which standards are imposed). Constraints are a function of assets, including productive assets and human capital, which can be private, collective, or public.

Within the constrained optimization framework, a firm (such as an urban retailer or processor, or an urban or rural wholesaler) has to decide on the design of the supply chain used to source inputs and market outputs. Du et al. (forthcoming) decompose the "optimal supply chain choice of the innovator" to six detailed choices: (1) production quantity given capital constraints and market conditions; (2) in-house versus purchased supplies (upstream this means deciding how much feedstock to grow vs. purchase from other farmers, midstream is inventory levels, and downstream is creation of marketing services in-house or outsourced); (3) for purchased supplies, whether to buy through contracts or spot market arrangements; (4) when using contracts, what terms and conditions to include; (5) for in-house production, what technology to use; and (6) how the degree of monopsony and monopoly, and government regulations that affect market power, change the choices made for these five considerations. These basic questions form the basis from which a supply chain is designed. The vulnerability or resilience to climate shocks are derived from the nature of the supply chain (controlling for the climate shock) which in turn is formed by design decisions of firms using them.

All else equal, a short-term climate shock reduces profit for these firms. To attenuate profit loss, firms or farms need to innovate and make investments to manage risks ex ante or cope with shocks ex post, at a type and level appropriate for the nature of risk. We follow a long literature on investment and call these "threshold investments" (Hubbard 1994). Typically, a firm or farm would make the threshold investment itself to mitigate the effects of a shock. At times, a mitigation measure taken by a single firm provides external economies to firms around it (or up or 
downstream from it). An example could be a firm constructing a culvert that diverts flood water not just from it but also from those physically downstream from it.

Moreover, the needed threshold investments (and returns to these investments) will be conditioned by the sources of vulnerability related to the seven determinants of hotspots discussed above. We surmise that there is a greater possibility for threshold investments to reduce risks on some determinants of hotspots (such as physical infrastructure to reduce production risks) than others (like intensity and robustness of physical capital). In addition, we expect the risk mitigation strategy of a firm in an area of very low density of physical capital or non-robust physical capital to be different than that of one in area of high density of capital and high robustness. There are also mutual externalities of items of capital stock in a given area; for example, if a sea wall is fragile or flimsy a mitigation investment in flood control canals next to it would be ineffective. By contrast, there could be a positive externality where pond lining reinforcement is undertaken in an aquaculture area bordering the sea where strong sea walls have been erected.

A key point is that not all zones, firms, and farms will be able to make the needed threshold investments. The challenge is exacerbated by the need for ex ante investments - implying an investment, credit, and planning horizon foreign to small firms and farms. This can create a kind of "poverty trap" (Carter and Barrett 2006) caused by climate shocks and accompanied by exclusion of certain zones, firms and farm strata. This can lead to a concentration of the segments of supply chains, such as when large processing firms gain market share after a shock. It can lead either to concentration of zones where the product is produced, or a shift toward new zones (similar to what can happen in long-term climate change discussed below).

The threshold investments cum strategies of managing risk from short-term climate shocks or coping fall into several categories. A major distinction is between large, transnational companies and smaller, domestic companies. For example, firms and farms may need to temporarily or permanently switch away from supplying zone or intermediate point. This of course is done constantly in international trade, such as the example of a US fruit processing firm recently shifting from Mexico to China to Argentina as costs changed. Some large companies do the same in large domestic markets, such as Charoen Pokhpand (CP) building compartmentalization of its supply chains in Asia to allow switching from one source zone to another after a climate shock. International sourcing also diminishes climate shock risk by having a more diversified network of suppliers with low degree of correlated exposure to climatic risks.

Such investments are less easy for most domestic sourcing, which we noted is $90 \%$ of the food supply of Africa and Asia. The challenges can be substantial for several reasons. First, there may be no cost-effective sourcing alternative in the short run, either in terms of switching from long distance to "local" sourcing, or switching to another zone. This difficulty may be more acute for urban-rural and rural-rural supply chains as the web of transport routes and the economic sourcing distances for rural consumers may be more limited for these supply chains. By contrast, rural-urban supply chains utilize a more extensive web of transport links including large highways, radiating from and to a large city. 
Second, another zone might be available but lack prior requisite investments to meet the buyer's requirements. An example is the requirement by most European retailers for perishables suppliers in developing countries to have GLOBALGAP certification. This would involve "asset specificity" of investments, often substantial, by suppliers in a given zone (and typically by larger producers). If the buyer suddenly had to switch zones, it may well not be able to find the qualified suppliers. Again, this challenge might be more acute for the rural-rural and urban-rural supply chains than for the urban-rural chains, but the issue is present for all three depending on the product and the degree of transformation of the market.

A similar challenge might go for a range of post-harvest transport and processing facilities that would be needed to source. Moreover, a large buyer with standards needs to provide an ongoing incentive for suppliers to make investments in the requisite quality and so on. If the buyer is seen to be risky as a client, farmers, processors, and distributors will shy away from making needed relation-specific investments for that client. The buyer would need to maintain a minimum of demand from that zone or set of suppliers to maintain the incentive.

Third, the business management literature references the need to reduce lead time and "increase agility" to avoid risks or cope with shocks (Ponomarov and Holcomb 2009). This involves investing in alternative arrangements to existing suppliers or supply routes and systems, all of which are costly. For example, CP built "redundant ports" for rice supply from Thailand to its foreign markets, building several ports along rivers to provide alternatives in the case of a typhoon or tidal wave. With the growing need for these investments in the face of increased climate shocks, market concentration in larger firms will likely increase.

As a consequence of the above challenges, firms and farms may make induced innovations in "climate proofing" or "climate adapting" their equipment and processes. Firm-level investments might include energy saving or less energy dependent equipment (e.g. larger equipment), larger and more vehicles, and more rapid transport (to reduce inventories "held hostage" to climate shocks). Firms may also invest in enhanced storage through driers and dehumidifiers or stronger storage (for example ${ }^{1}$ investment by a cocoa cooperative in typhoon-proofed cocoa containers in Vanuatu), and increased access to information flows for better "supply chain intelligence" as well as purchase insurance policies, where available. Finally, firm-level investments may seek to enhance supply chain-level efficiencies. At the government- and community-level, investments could seek to reinforce and/or build deepwater/off-shore ports (as in Indonesia, Shanghai, Rabobank), increase resilience in urban logistics, and seek to improve arrangements between governments for facilitation of shipping and supply (such as Hangzhou government did with Heilongjiang). Finally, an improved regulatory environment could further induce the private investments noted above, and create incentives and capacity for these investments.

\footnotetext{
${ }^{1}$ Personal communication Randy Stringer, Professor at University of Adelaide, July 2016.
} 


\section{Long-Term Climate Change Impacts on Transforming Food Supply Chains: Challenges and Strategies}

\subsection{Supply Chains and Melting Snow and Ice}

Climate change is increasing the likelihood and rate of melting snow and ice, which may have permanent effects on the economics of agricultural production in many regions. These changes in seasonal water availability patterns may result in floods and disrupt patterns of farm production. Melting snow and ice may change patterns of availability of water to irrigated agriculture. In locations such as close to the Himalayan mountains, there may be more floods during the rainy season and less water for irrigation during the dry seasons (Xu et al. 2009).

Intermediaries may suffer because flooding may harm infrastructure, including both storage facilities and roads, as well as affect the availability of supply. The risk of floods may necessitate moving processing and storage facilities, and may require added investment in transportation. Changes in patterns of farm production and the availability of food supplies may change procurement strategies of intermediaries as well as prompt them to invest in agricultural production in regions less vulnerable to these effects. Similar to mitigation measures done for short-term climate shock risks, some of the implications of the melting of snowcaps and ice can be mitigated by construction of dams or new storage facilities to protect against the increased flooding and to store water during the dry seasons (Xie and Zilberman 2016).

The response needed to large scale long-term climate change is of a far greater scale, and much greater investment requirements than are the mitigation measures made for short-term shocks discussed in the previous section. Thus there will be a need for public sector support; assembling resources for such grand investments can be politically challenging. Countries with superior governance system will be able to adapt more effectively to these long-term changes. Because many of these changes supersede national borders, for example Himalayan ice melt affects many countries, there is a growing role for multilateral organizations and international agreements. There will also be many opportunities for the private sector, at times in concert with the public sector, to intervene by investing in water projects. In some cases, organizations that have the financial capacity and creative ability to modify water patterns may become new important players in agricultural resource management. These water projects may include dams, hydropower facilities and other investments that will enhance agricultural productivity and provide a new source of value for the existing entities.

\subsection{Supply Chain and Migrating Weather}

There are many possible effects of migrating weather patterns on agriculture. Migrating weather will impact farm-level production and consideration of where to locate new production. With increasing knowledge of the evolution of changing 
weather patterns, agile firms may be able to exploit differences in impact across space by making strategic investments in land, processing facilities, and equipment. However, the gap between agile and non-agile firms and farms will be exacerbated. Finally, public research will be needed to support development and dissemination of technologies to adapt to, mitigate and slow migrating weather impacts.

One possible outcome is migration of crop production associated with specific weather. For example, production of certain dry wine varieties requires specific weather patterns. Increased heat may increase sugar content and may harm the ability to maintain wine quality. One solution may be to relocate production of grapes to another region (e.g. from California to Oregon). The production of wine also involves processing and shipping of grapes by wineries. Wineries have invested a lot in infrastructure and have recognized brand names. For instance, some of the reputation of wine is location-specific (e.g. high quality Bordeaux wine is produced only in Bordeaux). Thus, migration of weather may lead to migration of infrastructure and changes in regional and brand reputation, but also provide opportunities for other brands to grow or shift.

This will be a special challenge for denomination by locality/terroir, for example of cheeses and wines. Response by growers will vary. Growers in areas with warming weather may adapt their practices on-site to maintain location and quality, while other growers will shift location (such as wine production moving from Napa to Oregon). Further, with a migration of supply location, there may be a decline in terroir branding and a shift to marketing by variety (e.g., Cabernet) rather than by region, and an increasing importance of brand rather than location. This can induce further concentration in formerly location-bound industries as companies with good $\mathrm{R} \& \mathrm{D}$, branding and scale make alliances with growers in developing countries for contracted production of intermediate inputs based on detailed specifications. Of course to some extent this already occurs in commodity olive oil or wine, such as with Italian producers buying olives and grapes, first processed, from Eastern Europe and North Africa. This is also part of a larger trend where food industry companies source commodities (cheap bulk intermediate inputs) and market differentiated products, such as Smithfield Foods does in Europe by sourcing cheap pork from Eastern Europe and marketing quality branded products in France and Spain.

Large organizations that are aware of the differential impact of weather patterns that worsen productivity of certain regions (e.g. southern China), while increasing it in other regions (e.g. northern China), may invest and hold land resources to later build infrastructure for new agricultural production. Such behavior requires the ability to predict spatial differences in the evolution of climate change over time; that ability is still limited. However, as our understanding of patterns of climate change develop, we are likely to see more speculative investments in regions that may benefit from climate change. For instance, the projected water depletion/shortage in the Middle East is leading investors from those countries to buy land swaths in well-watered regions, such as in sub-humid Africa.

Given technological change in agricultural production processing and transport, weather migration may prompt more rapid transition to a modernized agricultural system as older facilities are retired. In this case, adaptation to climate change will 
have the unintended consequence of modernization - even vice versa, where modernization leads to adaptation. However, the extent to which this occurs depends on the ability to attract financial capital to areas most suited to expansion. It is quite likely that better managed, informed and more agile players, big or small, will be the ones that take advantage of these new opportunities.

Moreover, climate change may exacerbate differences between agile and nonagile actors. One of the main unintended consequences of climate change is an increasing of the gap between more traditional and less mobile farming communities with more entrepreneurial, mobile groups. This means that policies that assist in relocation and provide access to new opportunities may help overcome some of the negative distributional effects of adaptation to climate change.

Similarly, climate change may cause migration of farm workers from areas that suffer from worsening conditions. Migration is a difficult process and one may expect to see the emergence of networks of labor contractors that will enable movement of labor across regions. These types of labor movements are sometimes associated with illicit activities and human rights violations, and thus may require regulation and policy interventions, but the migration itself may provide better outcomes for people who live in regions that suffer from climate change.

Finally, one of the important challenges of public research is to develop and disseminate technologies that will slow the impacts of migrating weather. Even relatively small changes in temperature may have significant impact that require adaptation (Di Falco and Veronesi 2014). Moreover, slightly higher temperatures may increase vulnerability to pests and reduces chill days, which are required for blooming of some tree crops. Addressing these changes may require significant science-based adaptation. This may include new varieties better suited to changing agro-climatic conditions as well as practices to decrease the negative side effects of warming that may include new pests and shorter tree bloom. While government in developed countries may engage in supporting this type of research and development, in some developing countries the private sector may be engaged in pursuing appropriate technologies to assure availability of inputs. For example, multinationals which depend on the production of cacao, rubber, and other tropical crops, may engage in enhancing the capacity of producers to withstand the impacts of a changing climate. At the same time, these organizations may also encourage investment in production of these crops in new regions.

\section{Conclusions and Agenda}

In this chapter we emphasized several key points. First, it is important to analyze climate short-term shocks and long-term change on the full food supply chain (inputs, farms, processing, distribution). The farm is just one segment of the chain and accounts for only about half its costs and value added. The supply chain as a whole is important to food security and livelihoods (as employment) in both rural and urban areas. We identified three types of supply chains as important to rural and 
urban areas: rural to urban, urban to rural, and rural to rural. It is important to analyze all three in a dynamic context. Climate change and supply chains are dynamic phenomena. Analysis, and especially development of policies to affect the adaptation of all elements of supply chains to climate change, should take into account that supply chains are evolving and therefore be based on expectations of their future, rather than present, form.

Second, it is crucial to approach the analysis of climate shocks on supply chains with a clear view of the complexity of a given supply chain as an interdependent set of segments and sub-segments. Climate shocks upstream in the supply chain can disrupt a wide complex of midstream and downstream activities; a shock such as a flood in an intermediate area, which may impact assemblage and transport, can then block the sale of surplus from the rural area and ingress of input supply chains to farmers. These impacts could also block or delay supply to urban areas, which now constitute the majority of food consumption and markets in Africa and Asia, and rural areas, which now depend to a large extent on food supply purchases.

Third, it is important to analyze climate change impacts on supply chains from the viewpoint of "hot spots" of vulnerability along the chains, both before and after the farm gate. We identified seven determinants of these hot spots: physical infrastructure to reduce production risk in supply zones, geographic length of the supply chain, perishability of the product, intensity and robustness of physical capital, asset specificity cum location specificity, concentration, and exposure to climate risk. They vary enormously over locations and products and the degree of transformation of supply chains. This implies that solutions to climate risk for supply chains will need to be highly differentiated and adapted to the varying circumstances.

Fourth, it is important to view climate shocks, and strategies to mitigate them, from the point of view of (1) strategic supply chain design choices by actors along the supply chain, of sourcing and marketing systems, geography, institutions, and organization; and (2) threshold investments by actors (firms and farms) along all supply chains. It is thus crucial to understand the incentives and capacity of the actors in the segments of the supply chain, alongside the vulnerability of the segments in the case of insufficient or untimely incentive (or risk itself) or incapacity to make the needed investments. Moreover, it is probable that many small scale farms and firms will not be able to make the needed adjustments and investments and may fail because of climate shocks and ensuing supply chain adaptations undertaken by the leaders of the segments of the supply chains.

The above four points suggest a research agenda examining several dimensions of the climate change-supply chain interaction.

First, applied field research should study supply chains and understand their structure, conduct, and performance, and the variants of a given product's supply chains, geographically and by degree of transformation (traditional, transitional, modern).

Second, applied field research should analyze the vulnerabilities (potential and realized disruptions) of the supply chain by segment and by vector of impact, such as intermediate point flooding, energy constraints from stymied fuel supply chains, droughts in farming areas, and so on. 
Third, a study of the actors' strategies and constraints in both their design of and behavior in the supply chains should be done, with a particular application to understanding their choices and threshold investments to reduce their vulnerability to ( $e x$ ante) or cope with (ex post) supply chain disruptions due to climate shocks and changes.

Fourth, the research on innovation systems and public R\&D policies associated with climate change should be expanded to take into account all the components of the supply chain. It should consider allocation of efforts between public-private interaction in $\mathrm{R} \& \mathrm{D}$ activities throughout the supply chain, and the policies that can affect them.

Fifth, the research on climate change should emphasize policy and infrastructure investment constraints in the context of supply chains and identify potential areas to improve incentives and capacity of firms and farms and to facilitate public sector actions to make the needed climate adaptations.

\section{References}

Carter, MR and CB Barrett. 2006. "The economics of poverty traps and persistent poverty: An asset-based approach,” The Journal of Development Studies, 42(2): 178-199.

Di Falco, S., and M. Veronesi. 2014. "Climatic anomalies and conflicts: the role of tenure security on land disputes." Paper prepared for presentation at the EAAE 2014 Congress 'Agri-Food and Rural Innovations for Healthier Societies', August 26 to 29, Ljubljana, Slovenia.

Du, X., L. Lu, T. Reardon, and D. Zilberman. Forthcoming. 2016. "The economics of agricultural supply chain design: A portfolio selection approach," American Journal of Agricultural Economics, 98(5): 1377-1388; http://dx.doi.org/10.1093/ajae/aaw074

Elbehri, A. (ed.) 2015. Climate Change and Food Systems: Global assessments and implications for food security and trade. Rome: FAO.

Giorgi, F. (2006). Climate change hot-spots. Geophysical research letters, 33(8).

Hubbard, R. G. (1994). Investment under uncertainty: keeping one's options open. Journal of Economic Literature, 32(4), 1816-1831.

Kleindorfer, P.R. and G.H. Saad. 2005. "Managing Disruption Risks in Supply Chains," Production and Operations Management, 14(1), Spring: 53-68.

Liverpool-Tasie, L., Adjognon, S., \& Reardon, T. (2016). Transformation of the food system in Nigeria and female participation in the Non-Farm Economy (NFE). In 2016 Annual Meeting, July 31-August 2, 2016, Boston, Massachusetts (No. 236277). Agricultural and Applied Economics Association.

Nicholls, R.J. and A. Cazenave. 2010. "Sea-level rise and its impact on coastal zones," Science, 328, 18 June: $1517-1520$.

Oke, A. and M. Gopalakrishnan. 2009. "Managing disruptions in supply chains: A case study of a retail supply chain,” International Journal of Production Economics, 118(1), March: 168-174.

Ponomarov, S. Y. and M.C. Holcomb. 2009. Understanding the concept of supply chain resilience. The International Journal of Logistics Management, 20(1), 124-143.

Reardon, T. 2015. "The Hidden Middle: The Quiet Revolution in the Midstream of Agrifood Value Chains in Developing Countries," Oxford Review of Economic Policy, 31(1), Spring: 45-63.

Reardon, T. 2016. Growing Food for Growing Cities: Transforming Food Systems in an Urbanizing World. Chicago: The Chicago Council on Global Affairs. April.

Reardon, T. J.A. Berdegué, F. Echánove, R. Cook, N. Tucker, A. Martínez, R. Medina, M. Aguirre, R. Hernández, F. Balsevich 2007. Supermarkets and Horticultural Development in Mexico: 
Synthesis of Findings and Recommendations to USAID and GOM, Report submitted by MSU to USAID/Mexico and USDA/Washington, August.

Rosegrant, M.W., C. Ringler, and T. Zhu. 2009. "Water for agriculture: Maintaining food security under growing scarcity," Annual Review of Environment and Resources, 34: 205-22.

Swinnen, JFM (ed.). 2007. Global supply chains, standards, and the poor. CABI Press.

Tschirley, D., T. Reardon, M. Dolislager, and J. Snyder. 2015. "The Rise of a Middle Class in Urban and Rural East and Southern Africa: Implications for Food System Transformation," Journal of International Development, 27(5), July: 628-646.

Xie, Y. and D. Zilberman. 2016. "Theoretical implications of institutional, environmental, and technological changes for capacity choices of water projects," Water Resources and Economics, 13: 19-29.

Xu, J., R.E. Grumbine, A. Shrestha, M. Eriksson, X. Yang, Y. Wang, and A. Wilkes. 2009. "The melting Himalayas: Cascading effects of climate change on water, biodiversity, and livelihoods," Conservation Biology, 23(3): 520-530.

Zilberman, D., Zhao, J., \& Heiman, A. (2012). Adoption versus adaptation, with emphasis on climate change. Annu. Rev. Resour. Econ., 4(1), 27-53.

Open Access This chapter is distributed under the terms of the Creative Commons AttributionNonCommercial-ShareAlike 3.0 IGO license (https://creativecommons.org/licenses/by-nc-sa/3.0/ igo/), which permits any noncommercial use, duplication, adaptation, distribution, and reproduction in any medium or format, as long as you give appropriate credit to the Food and Agriculture Organization of the United Nations (FAO), provide a link to the Creative Commons license and indicate if changes were made. If you remix, transform, or build upon this book or a part thereof, you must distribute your contributions under the same license as the original. Any dispute related to the use of the works of the FAO that cannot be settled amicably shall be submitted to arbitration pursuant to the UNCITRAL rules. The use of the FAO's name for any purpose other than for attribution, and the use of the FAO's logo, shall be subject to a separate written license agreement between the FAO and the user and is not authorized as part of this CC-IGO license. Note that the link provided above includes additional terms and conditions of the license.

The images or other third party material in this chapter are included in the chapter's Creative Commons license, unless indicated otherwise in a credit line to the material. If material is not included in the chapter's Creative Commons license and your intended use is not permitted by statutory regulation or exceeds the permitted use, you will need to obtain permission directly from the copyright holder.

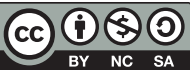

